\title{
Cirurgia pós-bariátrica do tronco superior: abdominoplastia em "Y"
}

\author{
The " $Y$ " pattern postbariatric surgery upper trunk reshaping
}

Luis Roberto Perez Flores ${ }^{1}$

Francisco Claro de

Oliveira Junior ${ }^{2}$

Antonio Gustavo Zampar ${ }^{1}$

José Marcos Mélega ${ }^{3}$

Trabalho realizado no Instituto de Cirurgia Plástica Santa Cruz, São Paulo, SP, Brasil.

Artigo submetido pelo SGP (Sistema de Gestão de Publicações) da RBCP.

Artigo recebido: $27 / 5 / 2010$ Artigo aceito: $25 / 8 / 2010$

\begin{abstract}
RESUMO
Introdução: Após grande perda de peso, observa-se flacidez de pele em várias regiões do corpo. O abdome com grande excesso de pele necessita da combinação de incisões mistas para correção desta flacidez com maior eficiência. Contudo, as incisões clássicas em âncora permitem o tratamento do abdome médio e inferior, entretanto não corrigem satisfatoriamente a flacidez epigástrica residual em alguns pacientes. Método: Seis pacientes previamente operadas de dermolipectomia abdominal em âncora e que mantinham flacidez epigástrica residual e mamária realizaram a mamoplastia com pedículo inferior associada à dermolipectomia reversa em âncora no mesmo ato operatório. Com seguimento mínimo pós-operatório de três meses, foram feitas avaliações desta nova técnica, quanto ao tempo de recuperação do paciente, viabilidade da técnica cirúrgica, complicações intra e pósoperatórias, características das cicatrizes, adequada correção da flacidez epigástrica e da ptose mamária e satisfação do paciente. Resultados: As cirurgias foram realizadas sem complicações intra-operatórias. As incisões utilizadas permitiram exposição adequada do campo operatório e facilidade no tratamento das estruturas abordadas com pequeno acréscimo à cicatriz da mastopexia na região esternal. Os pacientes apresentaram expressiva melhora do contorno corporal na região epigástrica e satisfatória correção da ptose mamária. Todos se mostraram satisfeitos com o resultado. Conclusão: A abordagem permitiu o tratamento da flacidez abdominal em epigástrio e correção da ptose mamária, com resultados satisfatórios, seguros e reprodutíveis para os pacientes com grandes perdas ponderais.
\end{abstract}

Descritores: Abdome/cirurgia. Mamoplastia. Obesidade. Cirurgia bariátrica.

\section{SUMMARY}

Introduction: After massive weight loss, there is a large amount of undesirable soft-tissue in many parts of the body. The breasts and the abdomen are usually the prioritary regions to be treated. However, the satisfactory treatment of the upper abdomen in postbariatric patients is sometimes a challenge for the surgeons. The reverse abdominoplasty do not satisfactorily correct the residual epigastric laxity in some patients with previously abdominal reshaping surgery, once this technique can not remove undesirable circumferential soft-tissue of the upper trunk. Methods: Six female patients who had undergone massive weight loss were treated with a new technique. This technique consists of a vertical reverse abdominoplasty with horizontal incisions through the submmamary folds and a simultaneous mammaplasty. Results: There were no serious complications. The technique allows satisfactory and simultaneous correction of: (1) the epigastric looseness, (2) the excess of skin of the armpit, (3) the dorsal rolls, (4) breast ptosis and (5) the lower inframammary folds with only a small addition to the mammaplasty scar in the sternal region. All patients reported being completely satisfied with the results obtained in the treated regions. Conclusion: The method described allowed for satisfactory correction of epigastric laxity and breast ptosis and was demonstrated to be a safe procedure for patients who had undergone massive weight loss.

Descriptors: Abdomen/surgery. Mammaplasty. Obesiy. Bariatric surgery.

\footnotetext{
1. Cirurgião Plástico do Instituto de Cirurgia Plástica Santa Cruz, Membro da Sociedade Brasileira de Cirurgia Plástica (SBCP).

2. Pós-graduando da UNICAMP; Médico Cirurgião Plástico do Instituto de Cirurgia Plástica Santa Cruz, Membro da SBCP.

3. Cirurgião Plástico Membro da SBCP; Rgente do Instituto de Cirurgia Plástica Santa Cruz.
} 


\section{INTRODUÇÃO}

Em pacientes com grande perda ponderal, observa-se flacidez de pele em várias regiões do corpo, sendo o abdome e as mamas frequentemente as primeiras regiões a serem tratadas ${ }^{1-3}$. Entretanto, o tratamento satisfatório do tronco superior em pacientes pós-bariátricos é, algumas vezes, um desafio para o cirurgião plástico. A incisão clássica, como a abdominoplastia em âncora, permite o adequado tratamento do abdome médio e inferior, mas não é efetiva para o abdome superior. A abdominoplastia reversa, embora possa melhorar a flacidez epigástrica não é capaz de corrigir adequadamente o excesso de pele circunferencial. Estas circunstâncias são muito frequentes em paciente com grande perda ponderal, pois o abdome com grande excesso de pele necessita de uma combinação de incisões (vertical e horizontal) para a adequada remoção da flacidez longitudinal e circunferencial $^{1,2,4}$.

São cada vez mais frequentes em nossos meio pacientes com grande perda de peso, que já realizaram cirurgias de contorno corporal e que permanecem com flacidez residual, principalmente na região epigástrica. Desta forma, propomos uma nova abordagem, capaz de tratar a flacidez epigástrica e a ptose mamária: uma abdominoplastia reversa em âncora combinada com mamoplastia; que descreve um "Y" em sua marcação pré-operatória e na cicatriz final. Este procedimento permite correção satisfatória e simultânea: da frouxidão epigástrica, do excesso de pele da axila, das dobras cutâneas dorsais, da ptose mamária e elevação dos sulcos submamários nos pacientes que perderam grande quantidade de peso e têm cicatriz mediana epigástrica prévia, resultante da gastroplastia bariátrica.

\section{MÉTODO}

Uma revisão da técnica de abdominoplastia vertical reversa ("fleur-de-lis" reversa) combinada com mamoplastia é apresentada. A técnica foi executada durante um período de seis anos, em seis pacientes do sexo feminino, com perda de peso maciça, que sofriam de frouxidão epigástrica e ptose mamária e apresentavam cicatriz abdominal mediana superior devido ao pós-operatório de gastroplastia bariátrica aberta.

A abordagem começa com a demarcação da pele abdominal em excesso a ser removido com estimativas feita por "pinch-testes" com o paciente em pé no pré-operatório. Com o objetivo de corrigir a flacidez vertical, a área a ser ressecada é definida, em sua margem superior, no sulco submamário bilateralmente. A linha de incisão inferior é estimada pela tração para cima dos tecidos moles em excesso do abdome até o sulco submamário (localização da cicatriz final). $\mathrm{O}$ excesso circunferencial da pele a ser corrigida é determinado

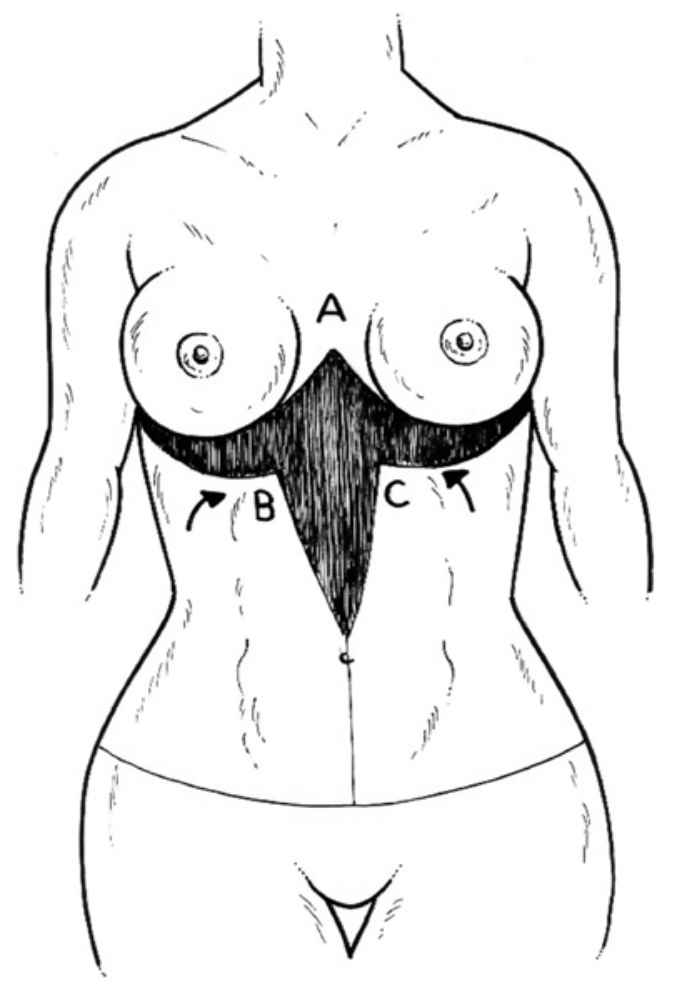

Figura 1 - Marcação abdominal inicial, realizada com a paciente em pé. A incisão abdominal superior é marcada no sulco inframamário e por "pinch test" a flacidez abdominal longitudinal é calculada. Da mesma forma, o excesso circunferencial é marcado na linha média abdominal.

por meio de um triângulo invertido localizado na linha média do abdome superior e inferior, demarcado por uma estimativa também feita por "pinch tests" (Figuras 1 e 2). A inclusão do umbigo ou não na área removida depende da quantidade de sobra de tecidos ou abaulamento residual neste local.

As incisões são feitas sobre a demarcação pré-operatória com bisturi número 22 através da derme e, em seguida, completa-se com eletrocautério até um plano sobre a aponeurose muscular. A incisão horizontal inicia-se no sulco submamário e o excesso de tecido a ser removido é reavaliado após o descolamento da área previamente demarcada e nova tração. As incisões verticais são realizadas de forma semelhante e a confirmação do excesso de pele a ser retirado é feito com trações bilaterais em sentido centrípeto. Após a ressecção do excesso de tecido mole indesejado, os tecidos vizinhos, que não foram descolados, são aproximados por planos, com pontos inabsorvíveis na fáscia de Scarpa e plano subdérmico, seguido por sutura intradérmica absorvível. Drenos a vácuo tipo Portovac são frequentemente colocados.

$\mathrm{Na}$ paciente que não teve qualquer cirurgia plástica anterior, uma minilipoabdominoplastia complementar 


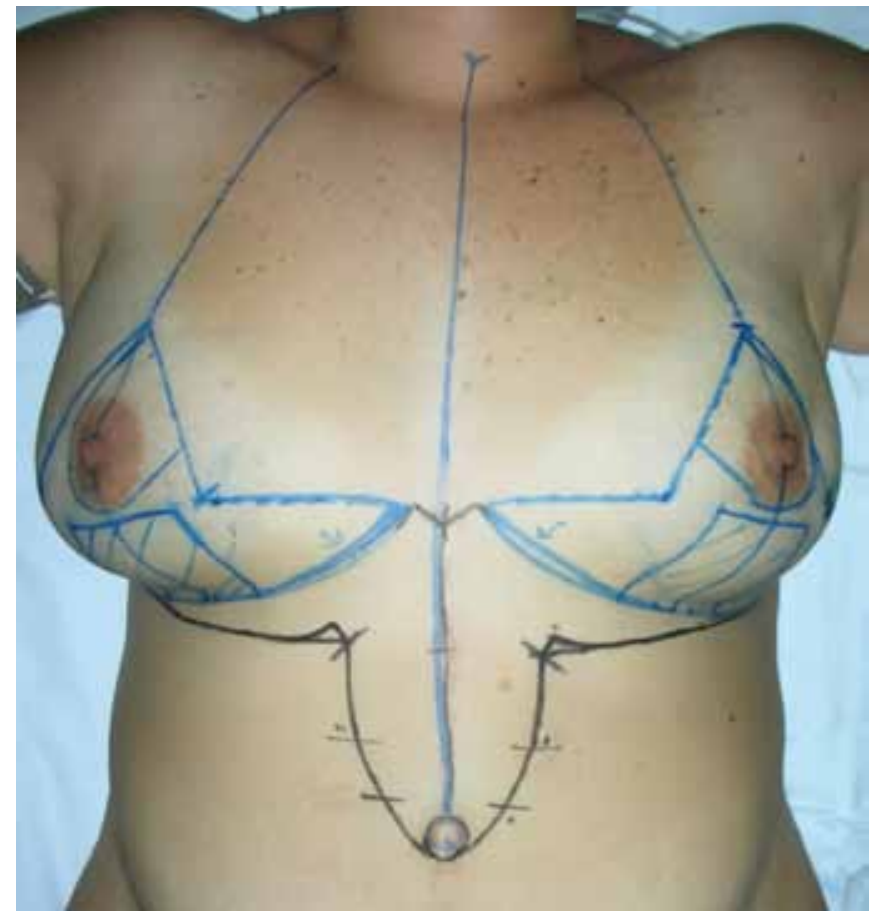

Figura 2 - Marcação pré-operatória da abdominoplastia em "Y. As incisões horizontais, incluindo os sulcos inframamários bilateralmente, determinam a margem superior da ressecção. A incisão inferior é determinada por tração, em direção superior, da flacidez abdominal, por meio de "pinch test". O excesso circunferencial é determinado também por "pinch test" na linha média (linhas pretas). Nesta paciente (paciente E), as mamas foram marcadas conforme preconizado pela técnica de Pitanguy (linhas azuis). É possivel observar a pequena cicatriz adicional resultante desta técnica marcada em linha preta na região pré-esternal, considerando que ela terá cicatrizes resultantes da mamoplastia (linhas azuis) e já tem uma cicatriz prévia na linha média do abdome superior. Observe a marcação final do excesso de tecido a ser ressecado que descreve um desenho em forma de " $Y$ ".

suprapúbica, com plicatura da aponeurose do músculo reto abdominal através de sutura inobservável intermitente, foi realizada para tratar a diástase muscular e a flacidez do abdome inferior.

\section{RESULTADOS}

Seis pacientes após grande perda ponderal por gastroplastia aberta do sexo feminino realizaram abdominoplastia reversa vertical associada a mamoplastia simultânea (abdominoplastia em "Y" - Figura 3), quatro delas devido ao excesso cutâneo e adiposo residual em região epigástrica após abdominoplastia em âncora clássica $(n=4)$, uma após abdominoplastia circunferencial $(n=1)$ e uma com excesso predominantemente epigástrico, sem cirurgia prévia de

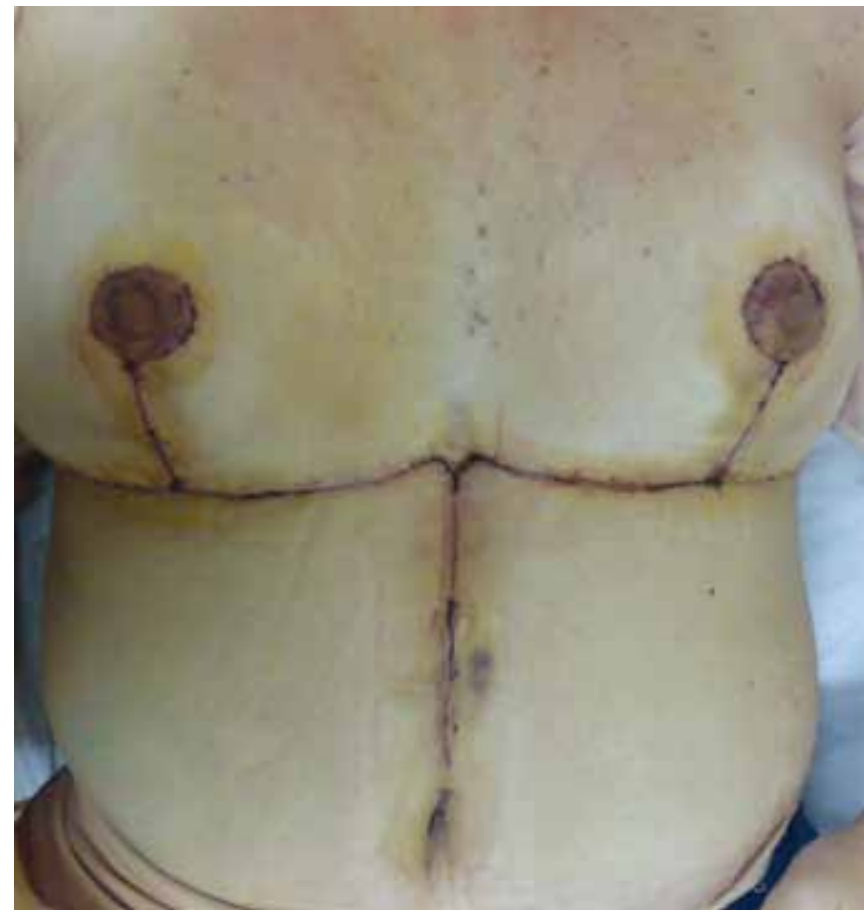

Figura 3 - Primeiro dia de pós-operatório com cicatrizes adequadamente posicionadas no sulco inframamário e linha média do abdome superior, também descrevendo a forma de um " $Y$ ”.

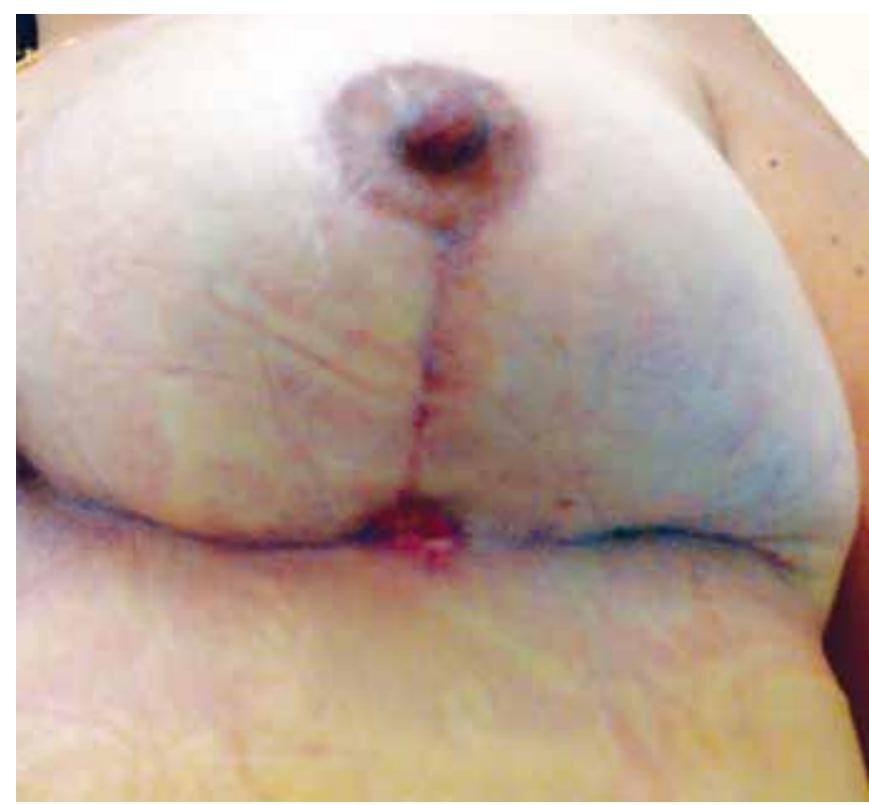

Figura 4 - Deiscência de aproximadamente $2,5 \mathrm{~cm}$ na junção das cicatrizes da mama esquerda observada no $14^{\circ}$ dia de pósoperatória (paciente E). Este foi um dos dois casos de complicação local observado neste estudo. A ferida teve cura completa com tratamento tópico sem sequelas. Embora a cicatriz tenha ficado levemente alargada, por estar bem posicionada no sulco inframamário, a paciente não desejou o seu retoque. 
Tabela 1. Resumo dos dados dos pacientes

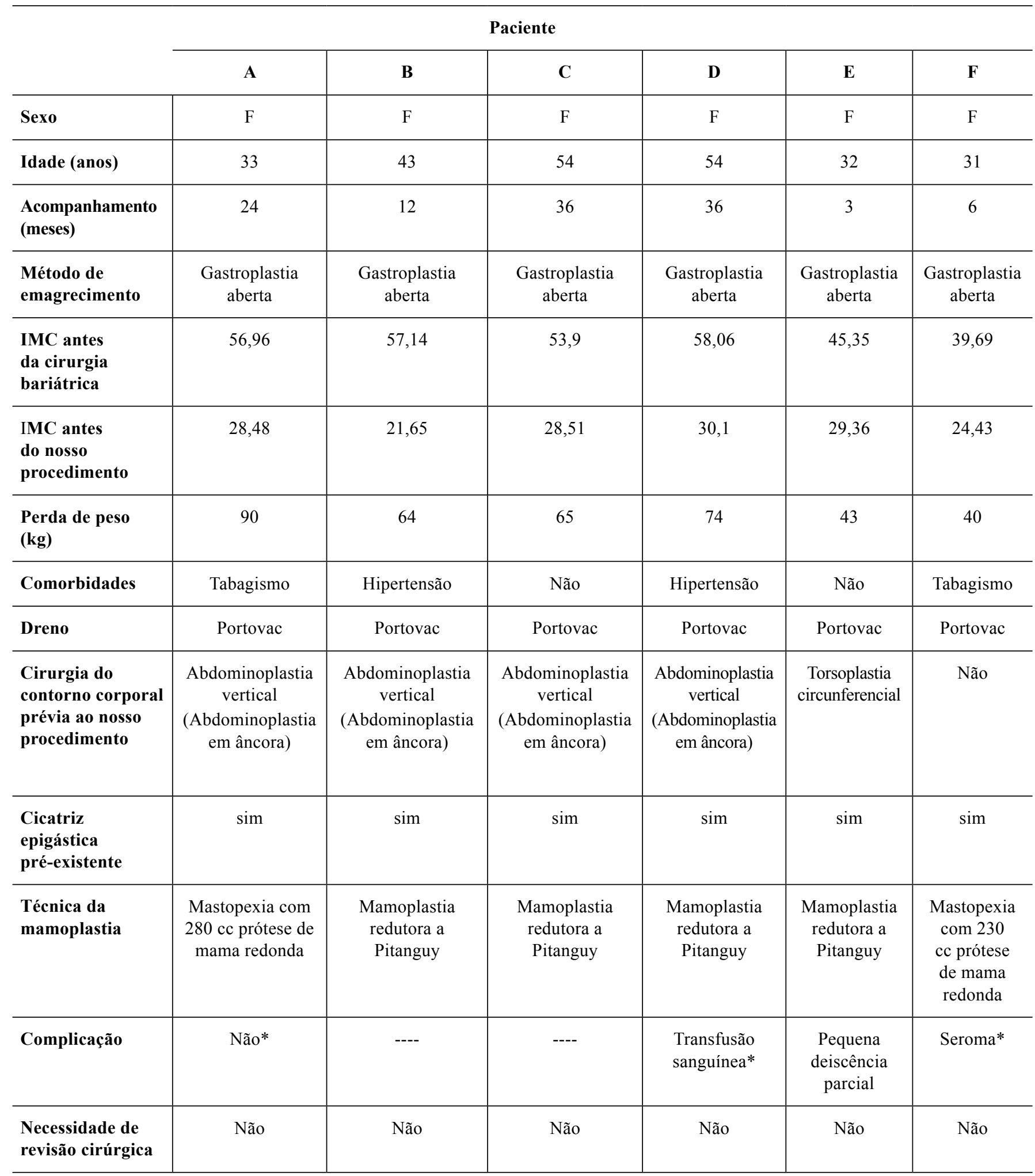

*Pequenas deiscências superficiais com menos de $0,3 \mathrm{~cm}$ (epiteliólise) em uma ou duas das cinco intersecções de cicatrizes que cicatrizaram espontaneamente sem qualquer intervenção em menos de uma semana. 

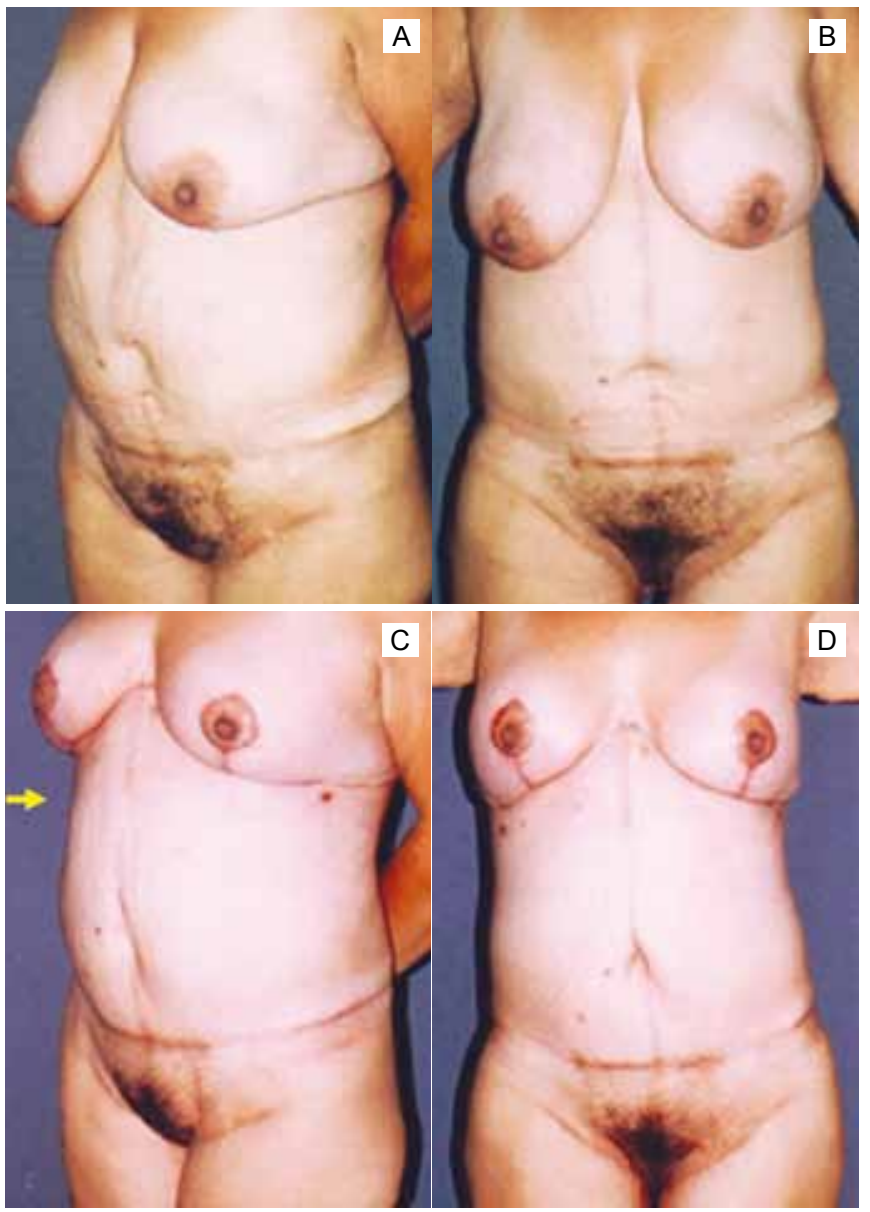

Figura 5 - Paciente de 43 (paciente B) que perdeu $64 \mathrm{~kg}$ após gastroplastia aberta, apresentando ptose mamária e importante flacidez epigástrica residual após nove meses de abdominoplastia vertical clássica. Fotos pré-operatórias (acima) e resultados pós-operatórios de 12 meses de abdominoplastia em " $Y$ " (fotos inferiores). Melhora no contorno das mamas e do abaulamento na região epigástrica (seta amarela).

contorno corporal $(\mathrm{n}=1)$. A idade média foi de $41,2 \pm 10,8$ anos, variando de 31 a 54 anos.

A abdominoplastia foi combinada em quatro pacientes com a mamoplastia clássica de Pitanguy e, em duas, foram realizadas mastopexia com implante mamário de silicone. $\mathrm{O}$ acompanhamento pós-operatório médio foi de 19,5 $\pm 14,7$ meses, variando de 3 a 36 meses.

Não houve complicações intra-operatórias. Embora tenha sido realizada adequada hemostasia durante a cirurgia, uma paciente necessitou de transfusão sanguínea imediatamente ao término do procedimento. Todas as pacientes apresentaram boa evolução pós-operatória imediata, recebendo alta hospitalar no dia seguinte ao procedimento.

Foram observados dois casos de complicações pós-operatórias tardias, um caso de seroma com resolução em uma semana após drenagem por punção percutânea com agulha fina em dias alternados, e um caso de deiscência parcial de aproximadamente $2,5 \mathrm{~cm}^{2}$ na junção das cicatrizes da mama esquerda (Figura 4). Este caso teve cicatrização completa com curativos locais. Não houve nenhum caso de hematoma, infecção, necrose tecidual, formação de quelóide, cicatrizes dolorosas ou flacidez residual das áreas tratadas. As cicatrizes ficaram com boa qualidade estética e adequadamente posicionadas no sulco submamário e linha média abdominal (Tabela 1).

As incisões permitiram ótima exposição do campo operatório, com adequado tratamento simultâneo das mamas e do abdome superior com o acréscimo de apenas uma pequena cicatriz entre as cicatrizes de mamoplastia convencional na região esternal (Figuras 2 e 3). Melhoras significativas no contorno e na forma das mamas e de toda a região abdominal foram observadas (Figuras 5 a 7). Todas as pacientes afirmaram estarem completamente satisfeitas com os resultados alcançados nas regiões tratadas.

\section{DISCUSSÃO}

As técnicas clássicas de abdominoplastia algumas vezes não são capazes de resolver o problema do excesso de pele e gordura residual na região epigástrica, frequentemente presentes em pacientes com grande perda ponderal. A abdominoplastia vertical reversa em associação com a mamoplastia, uma abordagem nunca antes descrita, tem se mostrado uma solução específica para este problema, especialmente para os pacientes que já têm uma cicatriz no abdome superior decorrente da gastroplastia aberta.

A abordagem permite simultânea e satisfatória correção: (1) do excesso de pele longitudinal, por meio das incisões horizontais localizadas nos sulcos inframamários, que podem ser estendidas posteriormente até a ponta da escápula, para a remoção adicional da flacidez axilar e dorsal $^{2-7}$, (2) da flacidez epigástrica circunferencial, por meio da incisão vertical na linha média abdominal, aplicando os mesmos princípios das abdominoplastias verticais clássicas $^{8-10}$.

Em adição, esta abordagem aproveita as incisões que são classicamente utilizadas para a mamoplastia ${ }^{11}$, uma vez que as incisões horizontais são efetivamente aplicadas à cirurgia das mamas e do abdome. A incisão vertical promove a remoção da cicatriz, comumente hipertrófica, resultante da gastroplastia aberta situada na linha média do abdome superior, comprovando, portanto, que não há aumento importante na extensão das cicatrizes.

A transfusão sanguínea realizada em um caso é reportado na literatura como um procedimento aceitável e, inclusive, esperado nas cirurgias de contorno corporal pós-bariátrica $^{12,13}$. Tivemos as mesmas taxas de complicações locais 

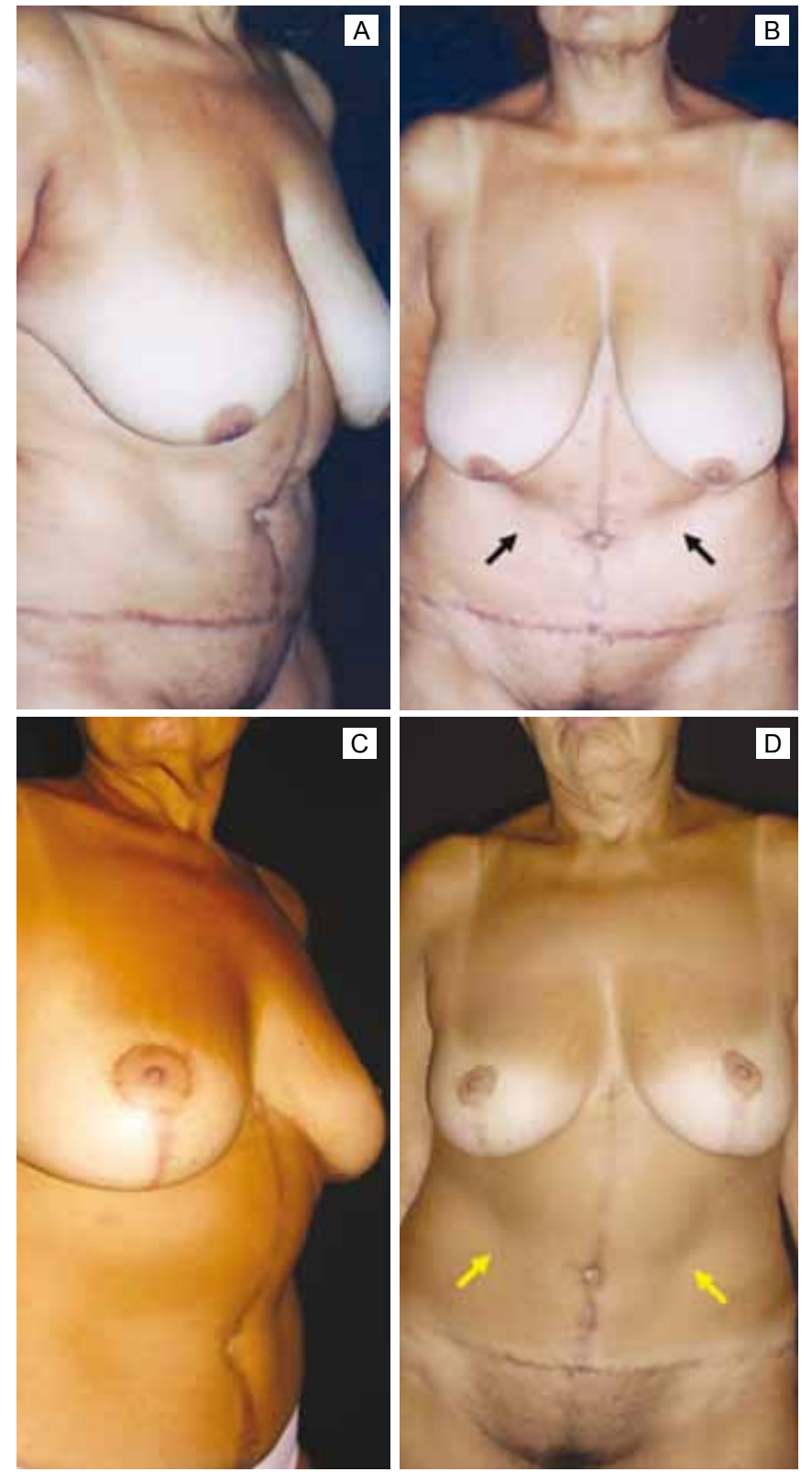

Figura 6 - Paciente de 54 anos (paciente C) que perdeu $65 \mathrm{~kg}$ após gastroplastia aberta em pós-operatório de 1 ano de abdominoplastia vertical clássica. Ela apresentava ptose mamária e importante flacidez residual em região

epigástrica (fotos superiores, pré-operatório). Trinta e seis meses de pós-operatório da abdominoplastia em " $Y$ " (fotos inferiores). Observe a significante melhora do contorno das mamas e da região epigástrica, que teve uma suavização após a remoção do excesso de pele e gordura (setas pretas demonstrando abaulamento epigástrico e setas amarelas, amenização das dobras de pele).
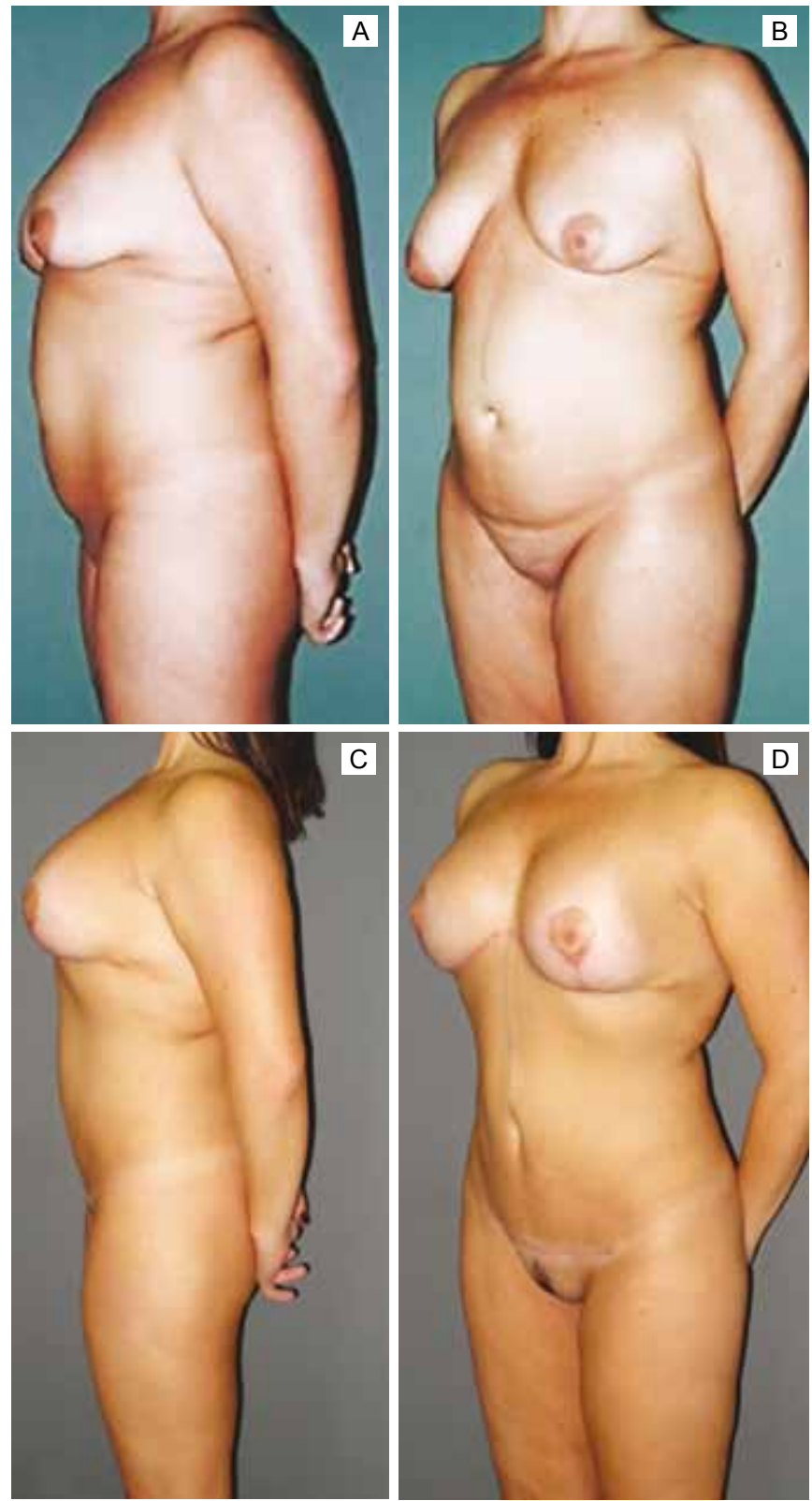

Figura 7 - Paciente de 31 anos (paciente F) após perda maciça de peso. Ela tinha uma cicatriz epigástrica devido a gastroplastia aberta, mas nunca tinha feito abdominoplastia. (Fotos superiores) Pré-operatório mostrando ptose mamária e redundância tecidual no abdome, particularmente em região epigástrica. (Fotos inferiores) Pós-operatório de 3 meses de abdominoplastia em

" $Y$ ", demonstrando excelente forma das mamas através de mastopexia com implante de silicone de $230 \mathrm{cc}$. O abdome apresentou grande melhora, principalmente na região superior. Nesta paciente, a abdominoplastia em " $Y$ " foi complementada simultaneamente com uma minilipoabdominoplastia suprapúbica com plicatura do músculo reto abdominal para o tratamento do abdome inferior. 
habitualmente relatadas para mamoplastias e abdominoplastias isoladamente ${ }^{12-18}$. Em adição, observamos resultados, para lidar efetivamente com a flacidez epigástrica, apenas obtidos por meio desta abordagem.

Apesar de não termos utilizados meios objetivos para quantificar a qualidade das cicatrizes ou a satisfação das pacientes, a abordagem teve grande taxa de "feedback" positivo das pacientes e de aprovação da equipe médica após comparação das fotos pré e pós-operatórias. Este resultados, obtidos inicialmente para as pacientes após gastroplastia aberta com flacidez epigástrica residual após abdominoplastia, nos estimulou a estender nossas indicações para pacientes que realizaram gastroplastia aberta com predominante redundância de pele e gordura em região epigástrica sem abdominoplastia prévia (paciente F).

Alimitação desta técnica inclui a combinação simultânea com abdominoplastia suprapúbica clássica nos pacientes com predomínio de flacidez em abdome inferior. Estas duas técnicas quando realizadas simultaneamente podem comprometer o suprimento sanguíneo dos retalhos abdominais e resultar em necrose $\mathrm{e}^{3,9,16,19,20}$. Uma forma de contornar este problema, quando indicado os dois procedimentos, é associar à abdominoplastia em "Y" a minilipoabdominoplastia do abdome inferior, como descrito por Saldanha et al. ${ }^{21}$ e conforme foi realizado na paciente $\mathrm{F}$ do presente estudo (Figura 7).

\section{CONCLUSÃO}

A abdominoplastia reversa em âncora combinada com a mamoplastia, abdominoplastia em "Y”, permitiu satisfatória correção simultânea da flacidez abdominal, predominantemente epigástrica, e da ptose mamária e demonstrou ser um procedimento seguro para os pacientes com perda ponderal maciça e sem cicatrizes adicionais importantes nas pacientes que realizaram previamente gastroplastia aberta.

\section{REFERÊNCIAS}

1. Akbas H, Guneren E, Eroglu L, Demir A, Uysal A. The combined use of classic and reverse abdominoplasty on the same patient. Plast Reconstr
Surg. 2002;109(7):2595-6.

2. Baroudi R. Body sculpturing. Clin Plast Surg. 1984;11(3):419-43.

3. Figueiredo JCA, Kawasaki MC. Tronco. In: Melega JMA, ed. Cirurgia plástica fundamentos e arte - cirurgia estética. Vol 3. Rio de Janeiro: Medsi;2003. p.433-705.

4. Hurwitz DJ, Agha-Mohammadi S. Postbariatric surgery breast reshaping: the spiral flap. Ann Plast Surg. 2006;56(5):481-6.

5. Rebello C, Franco T. Abdominoplasty through a submammary incision. Int Surg. 1977;62(9):462-3.

6. Wallach SG. Treating the abdominotorso region of the massive weight loss patient: an algorithmic approach. Plast Reconstr Surg. 2008;121(4):1431-41.

7. Halbesma GJ, van der Lei B. The reverse abdominoplasty: a report of seven cases and a review of English-language literature. Ann Plast Surg. 2008;61(2):133-7.

8. FischlRA. Vertical abdominoplasty. Plast Reconstr Surg. 1973;51(2):13943.

9. Franco T, Franco D, Medeiros-Filho JT. Dermolipectomia por incisão submamária. In: Resende JHC, ed. Tratado de cirurgia plástica na obesidade. Rio de Janeiro:Rubio;2008. p.303-8.

10. Babcock WW. On diseases of women and children. Am J Obstet Gynecol. 1916;74:596.

11. Baroudi R, Keppke EM, Carvalho CG. Mammary reduction combined with reverse abdominoplasty. Ann Plast Surg. 1979;2(5):368-73.

12. van Geertruyden JP, Vandeweyer E, de Fontaine S, Goldschmidt DP, Duchateau J. Circumferential torsoplasty. Br J Plast Surg. 1999;52(8):623-8.

13. Leahy PJ, Shorten SM, Lawrence WT. Maximizing the aesthetic result in panniculectomy after massive weight loss. Plast Reconstr Surg. 2008;122(4):1214-24

14. Cardoso de Castro C, Cupello AM. Analysis of 60 cases of simultaneous mammaplasty and abdominoplasty. Aesthetic Plast Surg. 1990;14(1):35-41.

15. Lanier VC Jr. Body contouring surgery after weight reduction. South Med J. 1987;80(11):1375-80.

16. Savage RC. Abdominoplasty following gastrointestinal bypass surgery. Plast Reconstr Surg. 1983;71(4):500-9.

17. Kim J, Stevenson TR. Abdominoplasty, liposuction of the flanks, and obesity: analyzing risk factors for seroma formation. Plast Reconstr Surg. 2006;117(3):773-9.

18. van Uchelen JH, Werker PM, Kon M. Complications of abdominoplasty in 86 patients. Plast Reconstr Surg. 2001;107(7):1869-73.

19. Gradinger GP, Rosenfield LK, Nahai FR. Abdominoplasty. In: Nahai F, ed. The art of aesthetic surgery: principles and techniques. Vol. 3. St. Louis:Quality Medical Publishing;2005. p.2351-422.

20. Mayr M, Holm C, Höfter E, Becker A, Pfeiffer U, Muhlbauer W. Effects of aesthetic abdominoplasty on abdominal wall perfusion: a quantitative evaluation. Plast Reconstr Surg. 2004;114(6):1586-94.

21. Saldanha OR, De Souza Pinto EB, Mattos WN Jr, Pazetti CE, Lopes Bello EM, Rojas Y, et al. Lipoabdominoplasty with selective and safe undermining. Aesthetic Plast Surg. 2003;27(4):322-7. 